\title{
Cross Sectional Survey of Pakistani Muslims Coping Health Anxiety through Religiosity during COVID-19 Pandemic
}

Qaisar Khalid Mahmood ( $\sim$ qaisar.khalid@iiu.edu.pk)

International Islamic University, Islamabad https://orcid.org/0000-0001-7009-5146

Malik Muhammad Sohail

Higher Education Department Punjab

Muhammad Babar Akram

International Islamic University, Islamabad

\section{Research Article}

Keywords: Covid-19, Religiosity, Coping, Muslims

Posted Date: August 27th, 2020

DOI: https://doi.org/10.21203/rs.3.rs-64185/v1

License: (1) This work is licensed under a Creative Commons Attribution 4.0 International License.

Read Full License

Version of Record: A version of this preprint was published at Journal of Religion and Health on March 11th, 2021. See the published version at https://doi.org/10.1007/s10943-021-01218-5. 


\section{Abstract}

This study aims to investigate the role of religiosity in coping with health anxiety during the outbreak of COVID-19, a deadliest pandemic of century which is still affecting billions of lives globally. Using online survey method, the researchers collected the data from 408 Pakistani Muslim respondents. Health anxiety and religious coping were measured through seven items Likert scales. Psychometric analysis showed that both scales, health anxiety (Cronbach's alpha $\dot{a}=.87$, composite reliability $C R=.869$ ) and religious coping (Cronbach's alpha á=.893, composite reliability $\mathrm{CR}=.888$ ), showed good internal consistency. Path analysis, structural equational modeling performed, was performed. All the fit indices (GFI=.932, $\mathrm{CFI}=.954, \mathrm{TLI}=.941, \mathrm{RMSEA}=.073 \& \mathrm{RMR}=.035)$ were within acceptable limit. The regression results indicated that those who were suffering with health anxiety opted religious coping $(\beta=.54, R 2=.29$, $p<.001)$. These findings can be helpful for psychiatrists, physicians and researchers to understand psychological complications pertaining infectious diseases.

\section{Introduction}

Coronavirus started affecting people initially in Wuhan (China) and soon this outbreak spread all over the world. Outbreak quickly led to large scale morbidity and mortality. It has aroused fear and panic in all societies. According to World Health Organization (2020a), novel coronavirus has spread across the globe affecting more than 10.5 million and killing more than 0.5 million people worldwide. In Pakistan, first case of Coronavirus appeared on $26^{\text {th }}$ February 2020 (Salman et al., 2020). Until now, 217,809 people are diagnosed while 4470 died due to coronavirus (WHO, 2020a). Unprecedented social, cultural and behavioral changes have been observed worldwide. Uncertainty about future, the boredom and questions about moral agency are substantial hazards caused by this pandemic (Hart, 2020). Though voices about mental health issues due to coronavirus have been raised through numerous platforms, identifying the mental health care needs of people impacted by this pandemic have been still neglected (Xiang et al., 2020).

Epidemics create an environment of uncertainty. A major outbreak can be followed by panic, fear, suspicion and stigma (Strong, 1990). In the face of such large scale crises, people go through complex decision making process of choosing something and skipping others (Abdulkareem et al., 2020). Infectious disease's outbreak can cause behavioral changes among large populations (Tan et al., 2004). Therefore choice of strategy emerges from complex social interaction (Ruland et al., 2015) and information available to decision makers (Zhao, Wu \& Ben-Arieh, 2015).

Psychological distress and stigma has been experienced by survivors during epidemics in recent past (James, Wardle, Steel \& Adams, 2019). After Ebola outbreak psycho-trauma was found among survivors along with numerous other ailments (Wadoum et al., 2017). In Sierra Leone (2014-2015 Ebola epidemic), Ebola survivors experienced obsession-compulsion, anxiety, hostility, phobic anxiety, and paranoid ideation (Ji et al., 2017). Similarly, Zika virus pandemic (2015-2016) ignited public anxiety (Blakey \& Abramowitz, 2017). A large sample of Chinese adults reported significant anxiety in the beginning of the 
coronavirus pandemic (Lee, 2020). Previous empirical studies report that individuals may experience symptoms of anxiety, psychosis, trauma, suicidal ideation and panic during outbreaks of communicable diseases (WHO, 2020b). Psychologists have highlighted a substantial need of psychological interventions in coronavirus outbreak in Pakistan to avoid any further crisis of compromised mental health of those suffering from coronavirus itself and those in self-isolation, social-distancing and quarantined (Mukhtar, 2020).

Studies on mental health issues pertaining coronavirus are largely recommending therapies and behavioral solutions to handle these issues in the face of this pandemic. Religious and spiritual coping strategies have been ignored though a few studies have alarmed about spiritual crises due to this pandemic (Lee, 2020). Contemporary psychology especially behaviorism needs to accommodate a healing power of faith (Levin, 2009). Levin (2010) argues religion's impact on mental health can be viewed through all the major lenses of modern psychology including behaviorism, psychodynamics, humanism, and transpersonalism.

A few studies have investigated the experiences of healthcare workers and general population during SARS and Ebola outbreaks. However this is first study in Pakistan as the country is affected by coronavirus only. Growing fear of infection and moral distress is often being experienced in social isolation that raises the concerns about anxiety associated with coronavirus (Peteet, 2020). In addition, this pandemic has severely limited the religious and spiritual activities of meeting together in religious services (VanderWeele, 2020) that was a great source of social support to cope with life stressors. This situation demands for self-care and availability of religious and spiritual resources to deal with mental health challenges. The impact of suspending religious activities on mental and physical health, role of the faith community in pandemic and religious involvement to cope with anxiety are important religious and spiritual aspect of life which need to be answered in this time of uncertainty when people have least control over their future (Hart \& Koenig, 2020). Religion, science and government are important institutions which provide coping resources to deal with stress, fears or threats (Hong \& Handal, 2020).

In this study we explore how people use religiosity as coping strategy in the face of health anxiety caused by Covid-19. Understanding how people respond to such outbreak is important in building resilience to such crises in the future.

In the past couple of decades, interest in scientific study of religion and health has exponentially risen. Consequently, a voluminous literature is available on effect of religious coping on physical and mental health. Religious spiritual beliefs provide coping responses to stress, provide reasoning for emotional and physical suffering that can facilitate acceptance and adjustment (Wortmann \& Park, 2008). Religious coping comprises of cognitive or behavioral techniques coping strategies often stem directly from an individual's religious beliefs system, help individuals during stressful life events (Tix \& Frazier, 1998). Studies reveal that religious resources predict emotional and spiritual well-being for long-term health related stressors (Gall, 2000). Religious and spiritual faith can be a source of comfort and strength for those who are in fear and suffering from this pandemic (Levin, 2020). A recent study (Huang \& rong Liu, 
2020) from China revealed the significance of emotion focused coping strategies in the face of coronavirus related distress. Emotion focused coping strategies also included religious element. Biographical descriptions of people in Italy suggest that spiritual skills for healthcare workers, patients and their families are important in Coronavirus disaster to relieve stress and psychic sufferance (Chirico \& Nucera, 2020).

\section{Methods}

\section{Study Rationale}

This study was conducted in the month of April, 2020. It was regarded as initial time period of outbreak of novel coronavirus in the country. The first case in the country was reported on $26^{\text {th }}$ February. In the month of March, the suspected cases of novel coronavirus were reported from all major cities of Pakistan. In response to slow down the outbreak, the government of Pakistan announced a national level lockdown in the country and directed all citizens to stay at home and practice social distancing while go outside in the case of emergency. Keeping in view the global condition due to pandemic and national level lockdown, this study was designed with the aim to investigate the psychosocial behavior of Pakistani people towards novel coronavirus. For this purpose, the authors were interested to assess the level of health anxiety among Pakistani people.

Pakistan, a country of 220 million people, is fifth most populated in the world and second in Muslim countries after Indonesia. As Muslim country, religion has pivotal role in the lives of people. This is why majority of the people seek guidance from religion whenever they are in trouble. In other words, people practice religion as a coping strategy whenever they are ill, facing a problematic situation and suffering mentally. The second objective of this study was that the people, who were suffering from health anxiety, opted religion/religiosity as a coping strategy.

\section{Data Collection}

We used online google survey for data collection as the country was locked down at the time of data collection. The authors shared e-link of study questionnaire on popular social media platforms (Facebook, Twitter, WhatsApp, and etc.). The respondents were requested to participate in the study on voluntary basis. Informed consent was taken from them. The authors provided a brief introduction of the study and principal author also shared his email contact with the respondents in case they had any question or difficulty in responding the questions. E-link of the questionnaire remained public for two weeks for data collection. A total of 408 respondents successfully completed the questionnaire.

\section{Study Variables}

Socio-demographic characteristics. to assess socio-demographic profile of the respondents, we asked the questions about age, gender, marital status, monthly family income and occupation of the respondents. 
Health anxiety: health anxiety is a well-researched concept in socio-psychology. There are various tools available to measure the level of health anxiety among people. We used short health anxiety inventory (SHAl) developed by Salkovskis et al. (2002) to measure health anxiety among common people. The SHAl contains 18 items that assess health anxiety independently of physical health status. Items assess worry about health, awareness of bodily sensations or changes, and feared consequences of having an illness. The SHAI has demonstrated good reliability, criterion validity, and sensitivity to treatment (Abramowitz, Deacon, \& Valentiner, 2007; Salkovskis et al., 2002). We have opted seven items related to anxiousness of common people in measuring health anxiety among Pakistani people.

\section{Religious Coping}

Multiple scales are available to sees religiosity among Muslim population. These scales are created on major Muslim religious practices (e.g. offering prayers, doing astaghfar and etc.). The authors reviewed these existing scales and adopted seven items. These items include; I regularly offer my prayers during COVID-19 pandemic, I seek forgiveness from Allah (astaghfar), Nowadays, I keep myself in Wudu (Ablution). Items were rated on five point Likert scale (Strongly disagree to strongly agree).

\section{Data Analysis}

The authors used IBM SPSS Statistics 21 to perform statistical analyses. Descriptive statistics were used to report the sample characteristics. Measures of central tendency (mean and standard deviation) were calculated with respect to each item. To assess internal consistency of health anxiety and religious coping, we computed Cronbach alpha coefficient (a), inter-item correlations, corrected item-total correlations and composite reliability. Path analysis, structural equational modeling, was performed to see the nature of relationship between health anxiety and religious coping.

\section{Results}

Table 1 


\begin{tabular}{|lll|}
\hline Variables & Frequency & Percentage \\
\hline Gender & & \\
\hline Male & 164 & 40.2 \\
\hline Female & 244 & 59.8 \\
\hline Perceived Social Class & & \\
\hline Lower Class & 17 & 4.2 \\
\hline Middle Class & 377 & 92.4 \\
\hline Upper Class & 14 & 3.4 \\
\hline Marital Status & & \\
\hline Not Married & 232 & 56.9 \\
\hline Ever Married & 176 & 43.1 \\
\hline Family Type & & \\
\hline Nuclear & 151 & 37.0 \\
\hline Joint & 244 & 59.8 \\
\hline Extended & 13 & 3.2 \\
\hline Area of Living & & \\
\hline Rural Area & 83 & 20.3 \\
\hline Sub Urban Area & 68 & 16.7 \\
\hline Urban Area & 257 & 63.0 \\
\hline Education & & \\
\hline Graduation and below & 212 & \\
\hline Post-Graduation & 196 & \\
\hline & & \\
\hline
\end{tabular}

Out of 408 respondents, 244 (59.8\%) were female, with approximately $63 \%$ living in urban areas. The study population ( $92.4 \%$ ) represented middle class of the society. Majority of the respondents $(59.8 \%)$ were living in the joint families and more than half of the respondents (56.9\%) were not married (See Table 1).

Table 2 presents the psychometric characteristics of health anxiety. The value of Cronbach's alpha $(\dot{\alpha}=.867)$ was well above than acceptable fit. All inter-item correlations were found significant and ranged between 0.37 and 0.75 . Moreover, corrected item-total correlations ranged between .56 and .749 . These 
statistics show that health anxiety scale had a good internal consistency. Mean analysis show that the respondents had an agreement with items no 1 and 4 . They did not agree with rest of the items.

Table 2: Psychometric properties of health anxiety scale

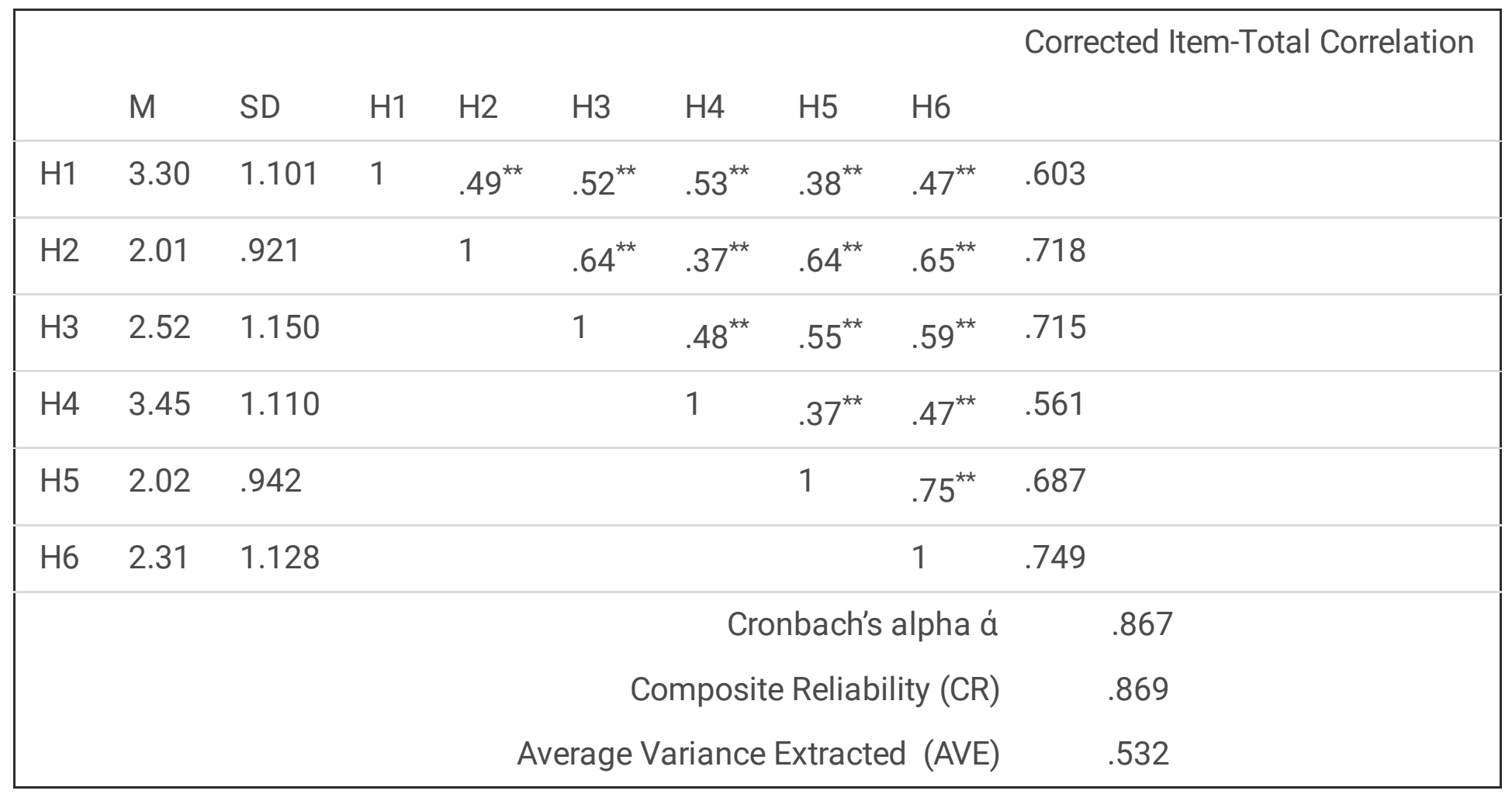

Psychometric analysis of the scale used to measure religious coping is presented in Table 3. Mean analysis show that the respondents had an agreement with all the items. The value of Cronbach's alpha $(\dot{a}=.893)$ was good. All inter-item correlations were found significant and ranged between 0.42 and 0.74 . Moreover, corrected item-total correlations ranged between .56 and .75 . These statistics indicated good internal consistency of religious coping scale.

Table 3: Psychometric properties of religious coping 


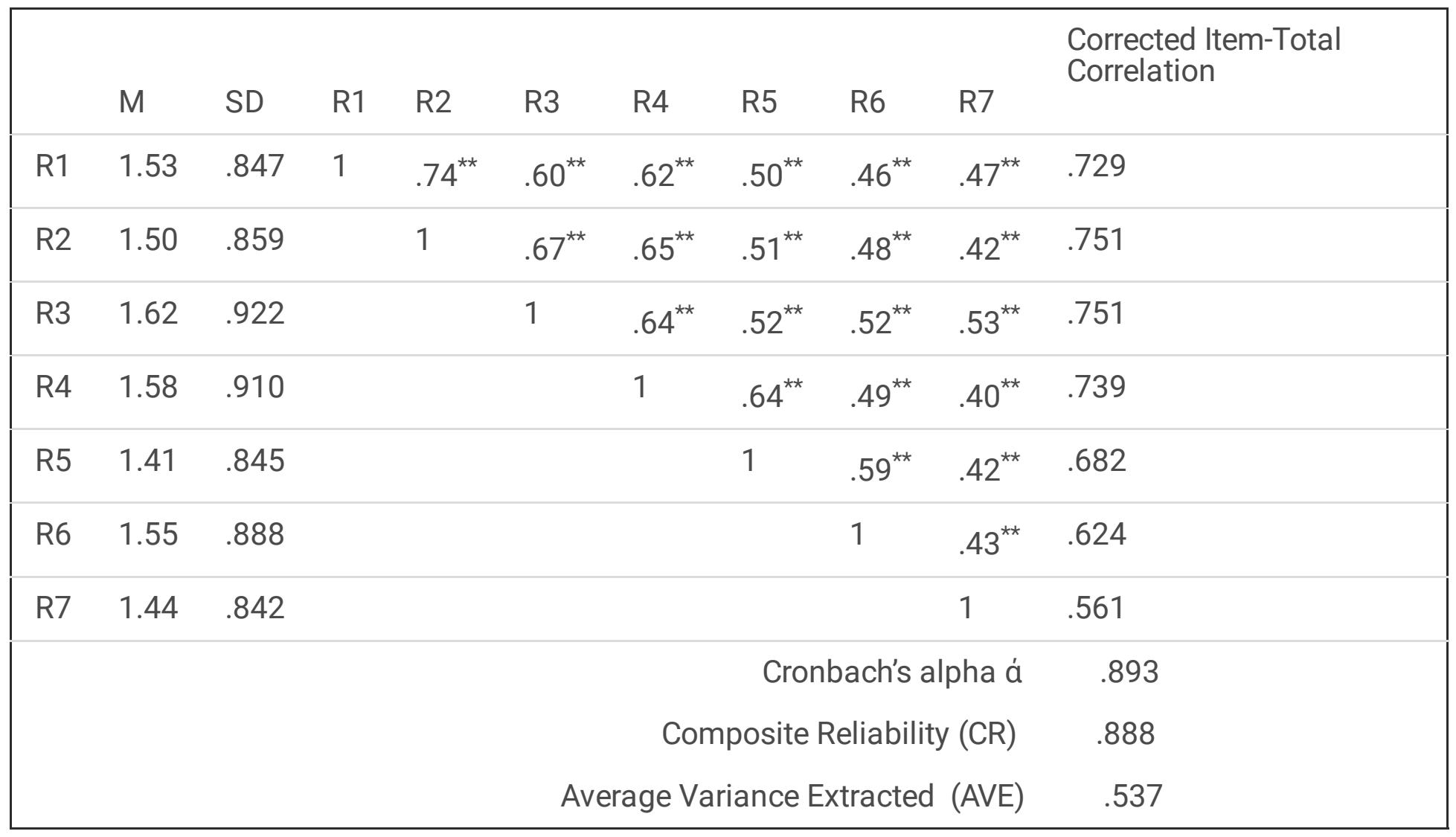

The authors conducted path analysis using AMOS. The results showed that fit indices were all within the acceptable limit $\left[\chi^{2}(61, \mathrm{~N}=408)=192.55, \mathrm{p}<.05 ; \mathrm{RMSR}=.035 ; \mathrm{RMSEA}=.073 ; \mathrm{GFI}=.932 ; \mathrm{TLI}=.941 ; \mathrm{CFI}=\right.$ .954]. For health anxiety, factor loadings were found statistically significant ranging from 0.53 to 0.86 . Similarly, factor loadings for religious coping were also found significant and within the acceptable range (.59 to .85$)$. Health anxiety had a positive relationship with religious coping $(\beta=.54, p<.001)$. The results showed that those who were anxious about their health did use religion as a coping strategy $\left(R^{2}=.29\right.$, $\mathrm{p}<.001$.

Table 4: Model fit indices of SEM model

\begin{tabular}{|lll|}
\hline Psychometric Testing & Value & Suggested Cutoff \\
\hline X2 (df) & $192.55(61)^{\star}$ & Non-significant \\
\hline Goodness of Fit (GFI) & .932 & $\geq .90$ \\
\hline Comparative fit index (CFI) & .954 & $\geq .90$ \\
\hline Tucker-Lewis index (TLI) & .941 & $\geq .90$ \\
\hline Root mean square error of approximation (RMSEA) & .073 & $<.08$ \\
\hline Root Mean Square Residual (RMSR) & .035 & $<.08$ \\
\hline
\end{tabular}




\section{Discussion}

The current study has conducted a psychometric analysis of two scales i.e. health anxiety scale and religious coping scale. Health anxiety scale has been found to have a good internal consistency among a sample of people quarantined during coronavirus pandemic. In addition, religious coping scale has also been found to have good internal consistency. A significant reason to gauge the psychometric properties of these scales was to apply them on a sample quarantined during a pandemic. Previously these scales have been used on diverse populations in non-pandemic settings. Along with the course of analyzing and refining these scales, other aim of this study was to explore the relationship between health anxiety and religiosity as a coping strategy.

The coronavirus pandemic has jolted masses in different psychosocial ways. Escalation in death toll of coronavirus affected patients and increased media reporting has created extremely stressful situation throughout the globe. Consequent mental health issues are not being addressed adequately due to huge number of effected (Xiang et al., 2020). Large scale tragedies like infectious diseases cause anxiety and fear in masses (Balaratnasingam \& Janca, 2006). Researches on previous viral disease outbreaks illustrated links between pandemic-related anxiety and high symptoms of stress, anxiety and posttraumatic stress (Yip et al., 2010). Latest studies reveal that mass quarantine can cause fear and community anxiety (Lima et al., 2020). Additional health problems particularly psychological issues caused by this pandemic demand serious collective consensus regarding daily behaviors, prevention strategies and decision-making (Torales et al., 2020). The statistical evidence from current study showed that health anxiety has a positive relationship with religious coping. These results suggest that those who were anxious about their health did use religiosity as a coping strategy. A plethora of literature reports that religious coping helps people in health related crisis (Sohail et al., 2019; Sohail, 2018; Zamanian et al., 2015). Huang \& rong Liu (2020) found that religion as component of emotion-focused coping has been used as coping strategy during the COVID-19 outbreak. These findings also corroborate results of another study which found students in Pakistan are using religious/spiritual coping in given situation of pandemic (Salman et al., 2020).

State of mental health problems and treatment resources is deplorable in Pakistan. The unavailability of psychologists, psychiatrists, psychiatric nurses, and social workers makes a large population of 220 million people vulnerable to miserable life (Bashir, 2018). Studies conducted in Muslim majority countries including Pakistan suggest that people suffering from psychiatric problems improvise faith healing for treatment (Ali \& Gul, 2018). However, all the studies currently conducted on mental health issues are ignoring religious and spiritual aspects of coping with a few exceptions. Researchers, psychotherapists and organizations dealing with mental health problems should pay attention towards religious and spiritual dimensions. They need to devise strategies for those who can't access mental health facilities so that they may use their faith for resilience and coping. In sum, the findings of this study suggest that health anxiety scale and religious coping scale are reliable and valid useful measures in times of epidemics. Future research can further explore the catalytic factors behind health anxiety. Health care professionals and researchers can conveniently use these scales. 


\section{Conclusion}

Coronavirus has caused health anxiety in Pakistani population just like other parts of the world. This study is one of the first studies which emphasized on religious and spiritual aspect of pandemic. Findings of this study have revealed that a significant proportion of people employed their religious and spiritual faith to cope with pandemic based anxiety. Policy makers, researchers and mental healthcare providers need to consider religious and spiritual factors while planning interventions to deal with mental health issues in the face of this pandemic.

\section{Declarations}

The authors declare no competing interests.

This study was approved by Ethics Review Committee, Department of Sociology, International Islamic University Islamabad.

\section{References}

Abdulkareem, S. A., Augustijn, E. W., Filatova, T., Musial, K., \& Mustafa, Y. T. (2020). Risk perception and behavioral change during epidemics: Comparing models of individual and collective learning. PloS one.

Ali, T. M., \& Gul, S. (2018). Community Mental Health Services in Pakistan: Review Study From Muslim World 2000-2015. Psychology, Community \& Health, 7(1), 57-71.

Balaratnasingam, S., \& Janca, A. (2006). Mass hysteria revisited. Current Opinion in Psychiatry, 19(2), 171-174.

Bashir, A. (2018). The state of mental health care in Pakistan. The Lancet Psychiatry, 5(6), 471.

Blakey, S. M., \& Abramowitz, J. S. (2017). Psychological predictors of health anxiety in response to the Zika virus. Journal of clinical psychology in medical settings, 24(3-4), 270-278.

Chirico, F., \& Nucera, G. (2020). An Italian Experience of Spirituality from the Coronavirus Pandemic. Journal of Religion and Health, https://doi.org/10.1007/s10943-020-01036-1

Gall, T. L. (2000). Integrating religious resources within a general model of stress and coping: Long-term adjustment to breast cancer. Journal of Religion and Health, 39(2), 167-182.

Hart, C.W. (2020). Spiritual Lessons From the Coronavirus Pandemic. Journal of Religion and Health, 59, 623-624. https://doi.org/10.1007/s10943-020-01011-w

Hart, C.W., \& Koenig, H.G. (2020). Religion and Health during the COVID-19 Pandemic. Journal of Religion and Health, 59, 1141-1143. https://doi.org/10.1007/s10943-020-01042-3 
Hong, B. A., \& Handal, P. J. (2020). Science, Religion, Government, and SARS-CoV-2: A Time for Synergy. Journal of Religion and Health, 1. https://doi.org/10.1007/s10943-020-01047-y

Huang, L., \& rong Liu, H. (2020). Emotional responses and coping strategies of nurses and nursing college students during COVID-19 outbreak. medRxiv.

James, P. B., Wardle, J., Steel, A., \& Adams, J. (2019). Post-Ebola psychosocial experiences and coping mechanisms among Ebola survivors: a systematic review. Tropical Medicine \& International Health, 24(6), 671-691.

Ji, D., Ji, Y. J., Duan, X. Z., Li, W. G., Sun, Z. Q., Song, X. A., ... \& Chen, G. F. (2017). Prevalence of psychological symptoms among Ebola survivors and healthcare workers during the 2014-2015 Ebola outbreak in Sierra Leone: a cross-sectional study. Oncotarget, 8(8), 12784.

Khan, S., Siddique, R., Li, H., Ali, A., Shereen, M. A., Bashir, N., \& Xue, M. (2020). Impact of coronavirus outbreak on psychological health. Journal of Global Health, 10(1).

Lee, S. A. (2020). Coronavirus Anxiety Scale: A brief mental health screener for COVID-19 related anxiety. Death Studies, 1-9.

Levin, J. (2009). How faith heals: A theoretical model. Explore, 5(2), 77-96.

Levin, J. (2010). Religion and mental health: Theory and research. International Journal of Applied Psychoanalytic Studies, 7(2), 102-115.

Levin, J. (2020). The Faith Community and the SARS-CoV-2 Outbreak: Part of the Problem or Part of the Solution?. Journal of Religion and Health, https://doi.org/10.1007/s10943-020-01048-x

Lima, C. K. T., de Medeiros Carvalho, P. M., Lima, I. D. A. S., de Oliveira Nunes, J. V. A., Saraiva, J. S., de Souza, R. I., ... \& Neto, M. L. R. (2020). The emotional impact of Coronavirus 2019-nCoV (new Coronavirus disease). Psychiatry research, 112915.

Mukhtar, M. S. (2020). Mental health and psychosocial aspects of coronavirus outbreak in Pakistan: psychological intervention for public mental health crisis. Asian Journal of Psychiatry. doi: $10.1016 /$ j.ajp.2020.102069

Peteet, J.R. (2020). COVID-19 Anxiety. Journal of Religion and Health, https://doi.org/10.1007/s10943020-01041-4

Ruland, E. C., Dinca, I., Curtis, V., Barry, M. M., Ekdahl, K., \& Timen, A. (2015). Learning from each other: where health promotion meets infectious diseases. Eurohealth incorporating Euro Observer, 21(1), 13-16.

Salman, M., Asif, N., Mustafa, Z. U., Khan, T. M., Shehzadi, N., Hussain, K., ... \& Khan, M. T. (2020). Psychological Impact of COVID-19 on Pakistani University Students and How They Are Coping. medRxiv. 
Sohail, M. M. (2018). Belief in God's help during hepatitis C: A qualitative study on Muslim patients in Pakistan. Journal of religion and health, 1-18.

Sohail, M. M., Mahmood, Q. K., Sher, F., Saud, M., Mas'udah, S., \& Ida, R. (2019). Coping Through Religiosity, Spirituality and Social Support Among Muslim Chronic Hepatitis Patients. Journal of Religion and Health, 1-15.

Strong, P. (1990). Epidemic psychology: a model. Sociology of Health \& IIIness, 12(3), 249-259.

Tan, X., Li, S., Wang, C., Chen, X., \& Wu, X. (2004). Severe acute respiratory syndrome epidemic and change of people's health behavior in China. Health education research, 19(5), 576-580.

Tix, A. P., \& Frazier, P. A. (1998). The use of religious coping during stressful life events: main effects, moderation, and mediation. Journal of consulting and clinical psychology, 66(2), 411.

Torales, J., O'Higgins, M., Castaldelli-Maia, J. M., \& Ventriglio, A. (2020). The outbreak of COVID-19 coronavirus and its impact on global mental health. International Journal of Social Psychiatry, 0020764020915212.

VanderWeele, T.J. (2020). Love of Neighbor During a Pandemic: Navigating the Competing Goods of Religious Gatherings and Physical Health. Journal of Religion and Health, https://doi.org/10.1007/s10943-020-01031-6

Wadoum, R. G., Samin, A., Mafopa, N. G., Giovanetti, M., Russo, G., Turay, P., ... \& Akpablie, J. (2017). Mobile health clinic for the medical management of clinical sequelae experienced by survivors of the 2013-2016 Ebola virus disease outbreak in Sierra Leone, West Africa. European Journal of Clinical Microbiology \& Infectious Diseases, 36(11), 2193-2200.

WHO (2020a). Health Emergency Dashboard. Accessed on July 03, 2020 from https://covid19.who.int/? gclid=EAlaIQobChMly9GLsqiw6gIVI9eyCh22iQ4gEAAYASAAEgK_hPD_BwE.

World Health Organization. (2020b). Mental health and psychosocial considerations during the COVID-19 outbreak, 18 March 2020 (No. WHO/2019-nCoV/MentalHealth/2020.1). World Health Organization.

Wortmann, J. H., \& Park, C. L. (2008). Religion and spirituality in adjustment following bereavement: An integrative review. Death studies, 32(8), 703-736.

Xiang, Y. T., Yang, Y., Li, W., Zhang, L., Zhang, Q., Cheung, T., \& Ng, C. H. (2020). Timely mental health care for the 2019 novel coronavirus outbreak is urgently needed. The Lancet Psychiatry, 7(3), 228-229.

Yip, P. S., Cheung, Y. T., Chau, P. H., \& Law, Y. W. (2010). The impact of epidemic outbreak: the case of severe acute respiratory syndrome (SARS) and suicide among older adults in Hong Kong. Crisis: The Journal of Crisis Intervention and Suicide Prevention, 31(2), 86-92. 
Zamanian, H., Eftekhar-Ardebili, H., Eftekhar-Ardebili, M., Shojaeizadeh, D., Nedjat, S., Taheri-Kharameh, Z., \& Daryaafzoon, M. (2015). Religious coping and quality of life in women with breast cancer. Asian Pacific Journal of Cancer Prevention, 16(17), 7721-7725.

Zarocostas, J. (2020). How to fight an infodemic. The Lancet, 395(10225), 676.

Zhao, S., Wu, J., \& Ben-Arieh, D. (2015). Modeling infection spread and behavioral change using spatial games. Health Systems, 4(1), 41-53.

\section{Figures}

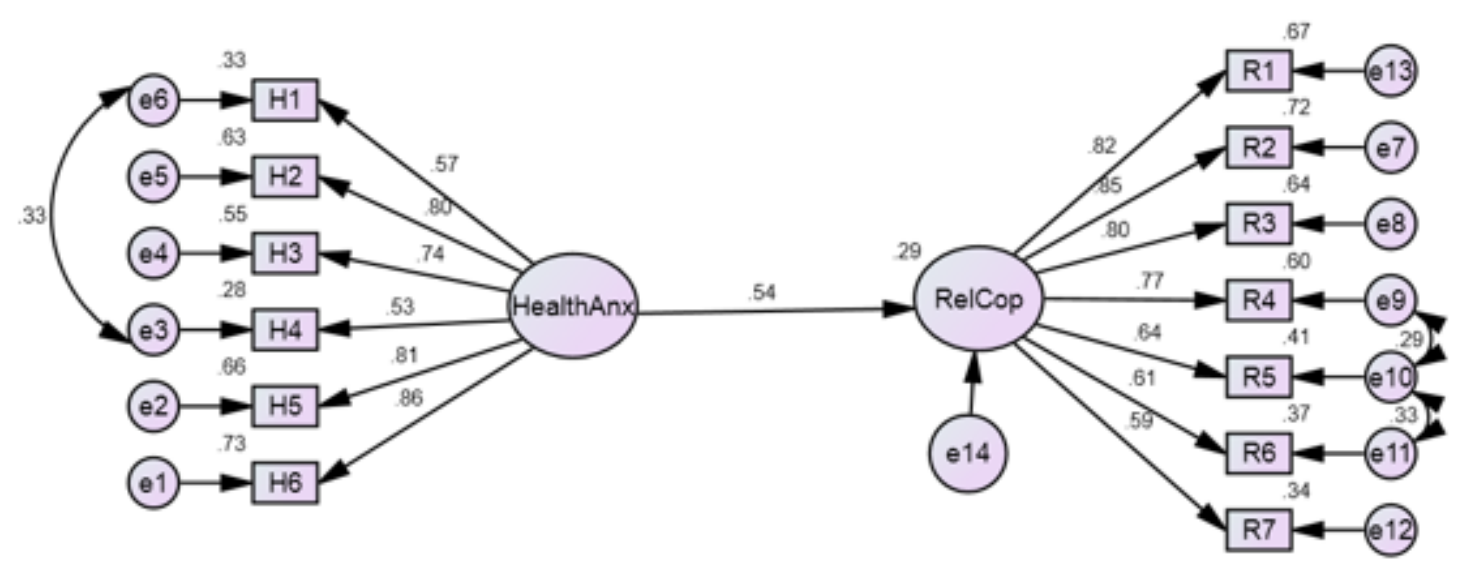

Figure 1

Path analysis between health anxiety and religious coping

\section{Supplementary Files}

This is a list of supplementary files associated with this preprint. Click to download.

- RG.amw 